Medical Education

\title{
The effect of communication skills training on residents' physiological arousal in a breaking bad news simulated task
}

\author{
Julie Meunier ${ }^{\mathrm{a}, \mathrm{b}, \mathrm{c}}$, Isabelle Merckaert ${ }^{\mathrm{a}, \mathrm{c}}$, Yves Libert ${ }^{\mathrm{c}}$, Nicole Delvaux ${ }^{\mathrm{a}, \mathrm{d}}$, Anne-Marie Etienne ${ }^{\mathrm{e}}$, \\ Aurore Liénard $^{\mathrm{a}, \mathrm{c}}$, Isabelle Bragard ${ }^{\mathrm{e}}$, Serge Marchal ${ }^{\mathrm{b}}$, Christine Reynaert ${ }^{\mathrm{f}}$, \\ Jean-Louis Slachmuylder ${ }^{\mathrm{b}}$, Darius Razavi ${ }^{\mathrm{a}, \mathrm{b}, \mathrm{c}, *}$ \\ a Université Libre de Bruxelles, Brussels, Belgium \\ ${ }^{\mathrm{b}}$ Psycho-oncology Center, Brussels, Belgium \\ 'Jules Bordet Institute, Brussels, Belgium \\ ${ }^{\mathrm{d}}$ Hôpital Universitaire Erasme, Brussels, Belgium \\ e Université de Liège, Liège, Belgium \\ ${ }^{\mathrm{f}}$ Université Catholique de Louvain, Louvain-la-Neuve, Belgium
}

\section{A R T I C L E I N F O}

\section{Article history:}

Received 7 February 2012

Received in revised form 17 April 2013

Accepted 27 April 2013

\section{Keywords:}

Communication skills

Training

Physiological arousal

Breaking bad news

Cancer

Psychology

\begin{abstract}
A B S T R A C T
Objective: Breaking bad news (BBN) is a complex task which involves dealing cognitively with different relevant dimensions and a challenging task which involves dealing with intense emotional contents. No study however has yet assessed in a randomized controlled trial design the effect of a communication skills training on residents' physiological arousal during a BBN task.

Methods: Residents' physiological arousal was measured, in a randomized controlled trial design, by heart rate and salivary cortisol before, during and after a BBN simulated task.

Results: Ninety-eight residents were included. MANOVA showed significant group-by-time effects. Trained residents' mean heart rate levels remained elevated after training and cortisol areas under the curve increased after training compared to untrained residents.

Conclusion: Communication skills training has an effect on residents' physiological arousal. Residents' self-efficacy and communication skills improvements in a BBN simulated task are associated with an elevated physiological arousal, which becomes proportional to the complexity of the task and reflects a better engagement and performance.

Practice implications: Residents should be informed that, to perform a task, they need to engage in the task with a physiological arousal proportional to the complexity of this task. Communication skills training should be adapted.
\end{abstract}

(c) 2013 Elsevier Ireland Ltd. All rights reserved.

\section{Introduction}

Improving physicians' breaking bad news (BBN) skills has been recognized as essential. Poor BBN may have a negative impact on patients' satisfaction with care [1], adherence to treatment [2], decisions about treatment options [3] and psychological adjustment [4]. Reviews about BBN have been published and there is now a wide consensus that $\mathrm{BBN}$ requires specific communication skills. In order to appropriately break bad news, physicians need to master communication skills promoting patients' expression of concerns but also to be able to identify cues as regards patients' needs and expectations in order to tailor information transmission step-by-step. BBN is a non linear, unscripted and highly complex

\footnotetext{
* Corresponding author at: Université Libre de Bruxelles, Av. Roosevelt, 50-CP 191, B-1050 Bruxelles, Belgium. Tel.: +32 265045 81/26 31; fax: +32 26502209 .

E-mail address: drazavi@ulb.ac.be (D. Razavi).
}

process both cognitively and emotionally for which physicians are not sufficiently trained [5-8].

Although reviews on BBN have insisted on the stressfulness of the BBN task, to our knowledge, only four studies until now have investigated physicians' physiological and psychological stress responses during BBN [9-12]. In the first study, medical students were randomly assigned to a bad news delivery task, a good news delivery task or a control task (reading magazines). This study, involving a limited number of subjects, showed that both bad news and good news delivery produced significant increases in selfreported distress and cardiovascular responses (heart rate and blood pressure) compared with the control task [10]. The second study found an anticipatory stress response among second year medical students to a simulated bad news consultation on cardiovascular measures (systolic blood pressure and heart rate) and subjective stress measures (globally assessed stress and state anxiety), compared with post-task measures [12]. The third study found higher cardiovascular responses in the bad news scenario

0738-3991/\$ - see front matter (c) 2013 Elsevier Ireland Ltd. All rights reserved. http://dx.doi.org/10.1016/j.pec.2013.04.020 
relative to the good news one [9]. Perceived stress, psychological distress and poor communication were not associated with increased cardiovascular responses in the bad news scenario contrary to doctors' inexperience and fatigue. The fourth study in a medical student population showed that BBN consultations provoked elevated heart rate responses compared to history taking consultations [11].

These four studies reported increased cardiovascular responses of doctors when faced with BBN. These heightened cardiovascular responses however were not systematically associated with subjective stress measures [9]. It is therefore essential to consider the subjective quality of responses when studying the impact of a task on physiological measures $[13,14]$. Physiological measures alone do not allow distinguishing physiological arousal as a sign of cognitive and emotional effort (investment of resources in order to perform a task) or of cognitive and emotional overload (and therefore of stress) [15]. This goes in line with Gaillard distinction between mental load and stress where mental load manifests itself as a temporary normal mental effort (a healthy coping strategy) whereas stress is seen as an enhanced activation that fails to improve performance and to facilitate recovery [16]. Hulsman et al. study suggests that part of the observed physiological response could also be attributed to the novelty of the task [11]. Beyond that, the impact of a stressor is also modulated by biological predispositions, personality patterns, learning history and available coping resources $[17,18]$.

In the last decades, communication skills training research programs have been conducted. These programs have been shown to improve not only physicians' and nurses' self-efficacy (subjective performance) [19] but also their communication skills (objective performance) [20-22]. No study however has yet assessed, in a randomized controlled trial design, the effect of a communication skills training on residents' physiological arousal in a BBN simulated task.

Yerkes and Dodson described an inverted-U relation between arousal and performance for numerous tasks (letter-detection, mood priming manipulation, public speaking, etc.). Moderate physiological arousal levels may therefore result in optimal performance, whereas too little or too much arousal may result in sub-optimal performances [23-26]. Physiological arousal levels have also been shown to be related to individuals' appraisal of their ability to perform a given task: when individuals perceive that they are unable to perform a complex task (threat appraisal), they may experience difficulties in engaging themselves in the task and their physiological arousal levels remain low, whereas when individuals perceive that they are able to perform a complex task, they experience less difficulties in engaging themselves in the task and their physiological arousal levels remain elevated (challenge appraisal) [26,27]. Yeo and Neal [28] moreover examined the relationship between motivation and performance during skills acquisition and reported that the relationship between effort intensity and performance increased with practice in the early phases of skills acquisition for tasks that involve complex information-processing demands.

The study objective was thus to assess training effect on residents' physiological arousal (Fig. 1). The response measures chosen in this study (heart rate and salivary cortisol) are different in terms of source systems, pattern of response, latency and potential impact or correlation with central mechanisms [29]. Given the complexity and duration of the task, it was considered that heart rate as an electrophysiological mechanism and cortisol as an HPA axis stress hormone would be mediating physiological arousal. Heart rate changes are usually reported to reflect attentional aspects of a task, such as cognitive processing of task-related information or cognitive appraisal of stressful situations [30], whereas salivary cortisol is a measure of affective

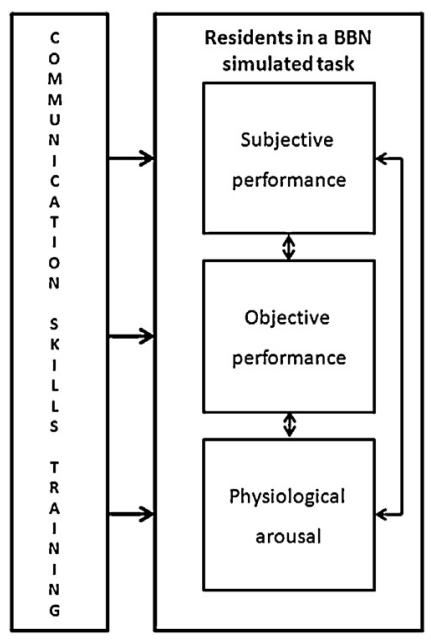

Fig. 1. Training effects on residents' performance and physiological arousal in a BBN simulated task.

responses to a task that is reported to be independent of the cognitive demands of a task and task engagement [31,32]. In a nonexperimental task as a BBN task, it is however impossible to distinguish both responses as both cognitive processing and affective responses are simultaneous.

It should be underlined that the efficacy of the training program assessed in this study has already been shown on residents' selfefficacy about their communication, on their ability to manage their stress to communicate (residents' subjective performance) [33], on communication skills (residents' objective performance) [22] but not on their burnout levels [33]. It was hypothesized that the improvement in subjective and objective performance would be associated with an increased mental effort invested in the BBN simulated task and consequently with an elevated physiological arousal. Trained subjects were expected to show an elevated physiological arousal, which is an indicator of their engagement to respond adequately to the task using newly learned communication skills while maintaining step-by-step attention to the task challenges.

\section{Methods}

\subsection{Ethics statement}

The Jules Bordet Institute's ethics committee approved of the study. Residents had to give their written informed consent.

\subsection{Subjects and study design}

All Belgian French-speaking hospitals were contacted with an internal letter of invitation to their residents working in cancer care $(n=2160)$. Because of the low response rate $(n=41)$, attending physicians and heads of department $(n=117)$ were contacted by phone. Six hundred and twenty-six residents, including the 41 potentially interested residents, were contacted by phone, 17 were individually met and 24 information sessions were organized.

To be included in this study, residents had to work with cancer patients, to speak French, and to be willing to participate in the training program and its assessment procedure. Residents participating in another communication skills training were excluded.

After the first assessment time, residents were randomly allocated to a 40 -h training (trained residents) or to a waiting-list (untrained residents) (Fig. 2). Assessments were scheduled before 


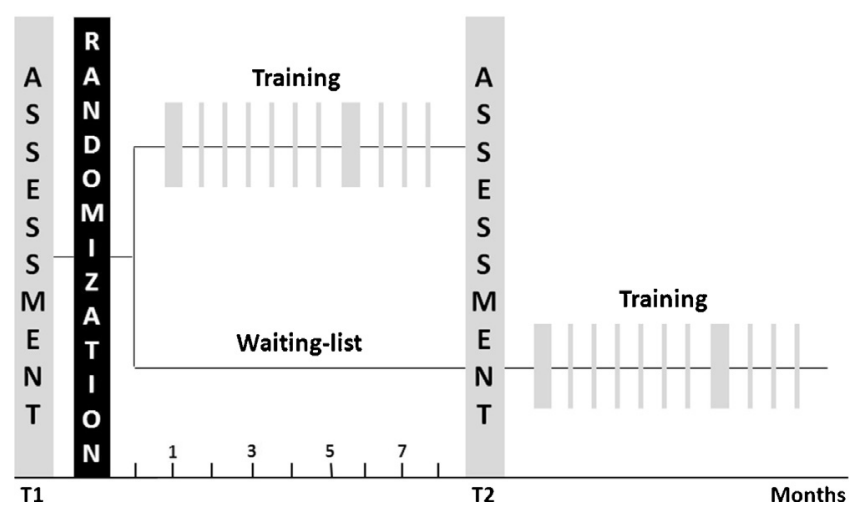

Fig. 2. Study design.

randomization for all residents and 8 months later for both groups (after training for trained residents and 8 months after baseline for untrained residents). Residents in the waiting-list were trained after the post-test assessment. The same assessment procedure was used at baseline and at post-test for both groups.

\subsection{BBN simulated task}

Residents' skills and physiological arousal were assessed in a standardized BBN simulated task as simulated tasks are a valid method to study communication style [34] and physiological arousal [10]. The simulated task consisted of a first medical encounter with an actress in which residents had to deliver a breast cancer diagnosis and to discuss treatment. The scenario was constructed to be complex (highly difficult cognitively and emotionally). The complexity of the task resulted from the medical situation (size of the tumor requiring mastectomy and chemotherapy) and the emotional consequences of the news on the patient. Three actresses were used during the study. The actresses were trained to exhibit a high level of distress at both assessment points when bringing up concerns about the medical and marital consequences of the disease. Training included practicing the roleplay and participating in regular feedback sessions led by the study coordinators. Each assessment procedure lasted from $10 \mathrm{am}$ to $12 \mathrm{pm}$ and consisted of four periods (Fig. 3). Before the BBN simulated task, residents had to complete questionnaires (rest period) and to learn the case description of the task (10-min preparation period). The BBN simulated task lasted $20 \mathrm{~min}$ and was audiotaped. Residents were asked to remain seated at the desk in order to minimize movement artefacts. Afterwards, residents had to complete questionnaires (30min recuperation period). The same assessment procedure was used at baseline and at post-test for both groups.

\subsection{Communication skills training}

The communication skills training program included a $30-\mathrm{h}$ communication skills training module and a $10-\mathrm{h}$ stress

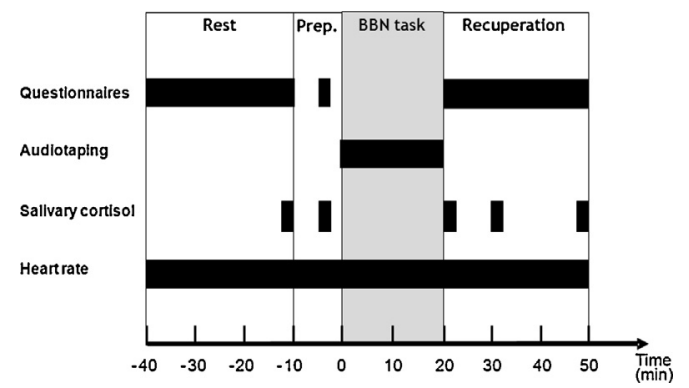

Fig. 3. Assessment procedure. management module. The training program was based on a previous communication skills training program which has been tested for its efficacy [35,36]. Sessions were spread over an 8month period and were organized bimonthly in small groups (up to 7 participants). The 30 -h communication skills training program consisted of a 17-h communication skills training focusing on twoperson interviews, a 10 -h communication skills training focusing on three-person interviews, and a last 3-h session promoting integration of learned skills. Among these $30 \mathrm{~h}$, a 1-h session focused on theoretical information. In the other sessions, residents were invited to practice communication skills through predefined role-plays focusing on BBN and role-plays based on the clinical problems brought up by the residents. Residents were given immediate feedback on the communication skills performed. The three phases of the BBN process were introduced gradually [22,37]. The choice of the skills taught was based on results of studies having shown the positive impact of using specific communication skills on patients' disclosure of concerns [38]. The 10-h stress management skills training included four $2.5-\mathrm{h}$ sessions. This program has been described in details in Bragard et al. [37].

\subsection{Residents' subjective performance}

Self-efficacy about communication was assessed, during the rest period, with a 13-item self-report questionnaire adapted from Parle et al.'s scale [39]. Adaptation of the scale consisted in the use of a 5-point Likert scale (from feeling not at all able to ... to totally able to...) and in the addition of items. This scale assesses residents' perception of their own ability to communicate with a cancer patient and to manage stress during communication. The adapted questionnaire showed low to adequate internal consistency reliabilities (Cronbach's alpha scores ranged from .61 to .79).

State anxiety was assessed, immediately before and after the BBN task, with the 20-item self-report State Trait Anxiety InventoryState form Ya (STAI-Ya) [40] assessing state-anxiety at the time of completion; the French-language version has been validated [41].

Satisfaction about performance was rated, during the recuperation period, on a $10-\mathrm{cm}$ visual analogue scale (VAS) assessing residents' satisfaction about their communication during the BBN simulated task.

\subsection{Residents' objective performance}

Communication skills were recorded during the BBN simulated task. Audiotapes were transcribed. Transcripts were analyzed by LaComm. LaComm is a French communication content analysis software. This software uses on the one hand a word count strategy based on categories of words like Protan [42] or Linguistic Inquiry Word Count [43] and on the other hand a word combination strategy like the General Inquirer [44]. The aim of this software is to analyze, utterance by utterance, verbal communication used by identifying utterances types and contents. This study considers only residents' utterances types. Utterances are categorized in three main types: assessment (open and open directive questions), support (acknowledgement and empathy) and information (procedural information, negotiation and other types of information) types. A more precise description can be found in Lienard et al. [22].

\subsection{Residents' physiological arousal}

Residents' physiological arousal was assessed by heart rate and salivary cortisol during the 2 -h assessment. This method has been validated in other studies [27,45]. Residents were instructed to abstain from food, alcohol, caffeine, nicotine for half an hour before the assessment, and from exercise for $24 \mathrm{~h}$ before it. 
Heart rate was monitored continuously using an ambulatory digital holter recorder (Lifecard CF Holter Recorder, Delmar Reynolds). The recorded heart rate was transformed in interbeat intervals (IBI) and automatically corrected for artifacts by a software (HRV Tools, Heart Rate Variability Software, Delmar Reynolds) and then hand-corrected. The recording was divided in nine periods: rest, preparation, BBN simulated task divided into 4 periods $(0-5,5-$ $10,10-15$ and $15-20 \mathrm{~min})$ and recuperation (0-10, 10-20 and 20$30 \mathrm{~min}$ ). Mean heart rate levels were calculated for each period and changes were computed between the different periods.

Salivary cortisol was collected by saliva samples at five timepoints: $10 \mathrm{~min}$ before the task (rest), just before the task (preparation) and 0,10 and $30 \mathrm{~min}$ after the task (recuperation). Areas under the response curve (AUCs) were calculated between the different time-points and for the entire 2-h assessment using the trapezoidal method as an indicator for the integrated cortisol response in the BBN simulated task [46]. As cortisol is a very sensitive response measure, all potential confounding variables (medication, food, alcohol, caffeine taken during the $24 \mathrm{~h}$ before the assessment procedure and number of hours of physical activity and sleep during the $24 \mathrm{~h}$ before the assessment procedure) were collected carefully and controlled for.

\subsection{Statistical analyses}

Statistical analyses included a comparative analysis of both groups of residents at baseline using parametric tests and nonparametric tests as appropriate (Student's $t$ test, MannWhitney test and $X^{2}$ test). To be considered for data analysis, residents had to attend at least $1 \mathrm{~h}$ of stress management and $1 \mathrm{~h}$ of communication skills training. This was done in order to limit the risk of bias associated with non-random loss of participants. We excluded residents who did not at all participate in the training program as their drop-out could not be attributed to the training in itself. Changes in residents' performance and physiological arousal were assessed using group-by-time Multivariate Analysis of Variance (MANOVA), General Linear Model or Generalized Estimating Equation Poisson Regression Models as appropriate. All tests were two-tailed, and alpha was set at .05. Analyses were performed with SPSS Version 17.0 for PC (SPSS Inc., Chicago, IL).

\section{Results}

\subsection{Residents' characteristics}

Fig. 4 describes the recruitment and assessment process. Principal barriers to participation were personal and institutional

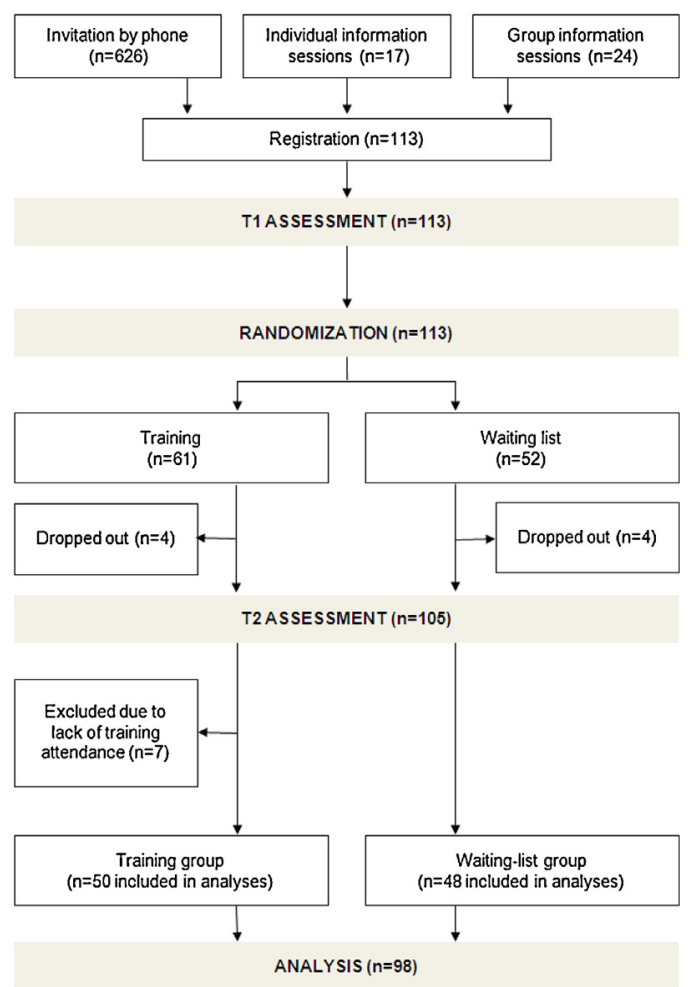

Fig. 4. Recruitment procedure, study design, training and assessment procedures.

reasons, time limitations, training duration, and time-consuming assessment procedures. Ninety-eight residents were included in the statistical analyses. Comparison of included and excluded residents showed no statistically significant differences for sociodemographic and socio-professional characteristics. For these characteristics, no statistically significant differences were found at baseline between trained and untrained residents except for specialty: untrained residents were more often residents in oncology $(p=.028)$. No statistically significant group-by-time difference was found regarding the number of cancer patients treated in the week before the assessments. Trained residents were a mean of 28 years old (SD $=3$ years) and $68 \%$ were female. They were on average in their third year $(S D=1.3$ years $)$ of residency. Six percent were residents in oncology, $32 \%$ in gynaecology and $62 \%$ in other specialties. Untrained residents were a mean of 28 years old $(S D=2.1$ years $)$ and $60 \%$ were female. They were on average in

Table 1

Training effects on residents' performance in a breaking bad news simulated task $(n=98)$.

\begin{tabular}{|c|c|c|c|c|c|c|c|c|c|c|c|}
\hline & \multicolumn{4}{|c|}{ Training group $(n=50)$} & \multicolumn{4}{|c|}{ Control group $(n=48)$} & \multirow{2}{*}{\multicolumn{3}{|c|}{$\begin{array}{l}\text { Statistical analyses }^{\mathrm{a}} \\
\text { Group by time effects }\end{array}$}} \\
\hline & \multicolumn{2}{|c|}{ At baseline } & \multicolumn{2}{|c|}{ After training } & \multicolumn{2}{|c|}{ At baseline } & \multicolumn{2}{|c|}{$\begin{array}{l}8 \text { months after } \\
\text { baseline }\end{array}$} & & & \\
\hline & Mean & SD & Mean & SD & Mean & SD & Mean & SD & $F$ & $\mathrm{RR}$ & $p$ \\
\hline \multicolumn{12}{|l|}{ Subjective performance } \\
\hline Self-efficacy about communication (before the simulated task) & 3.0 & 0.4 & 3.4 & 0.5 & 3.1 & 0.5 & 3.2 & 0.6 & 13.29 & - & $<0.001$ \\
\hline State anxiety (before the simulated task) & 45.7 & 7.7 & 43.2 & 6.6 & 44.5 & 9.4 & 42.4 & 8.4 & 0.08 & - & 0.782 \\
\hline State anxiety (after the simulated task) & 44.8 & 9.4 & 38.1 & 8.1 & 43.2 & 10.2 & 38.7 & 8.4 & 1.34 & - & 0.251 \\
\hline Satisfaction about performance (after the simulated task) & 32.4 & 19.0 & 52.5 & 22.1 & 39.4 & 20.0 & 46.7 & 21.9 & 5.96 & - & 0.017 \\
\hline \multicolumn{12}{|l|}{ Objective performance } \\
\hline Assessment (open questions and open directive questions) & 3.2 & 2.0 & 5.2 & 3.5 & 3.3 & 2.7 & 2.8 & 2.5 & - & 1.92 & $<0.001$ \\
\hline Support (acknowledgement and empathy) & 23.3 & 14.4 & 27.1 & 15.2 & 24.2 & 17.3 & 22.3 & 14.0 & - & 1.26 & 0.055 \\
\hline $\begin{array}{l}\text { Information (procedural information, } \\
\text { negotiation and other information) }\end{array}$ & 63.4 & 22.5 & 45.4 & 24.2 & 64.8 & 29.0 & 64.9 & 28.5 & - & 0.72 & $<0.001$ \\
\hline
\end{tabular}

There is one missing value for subjective performance measures $(n=97)$.

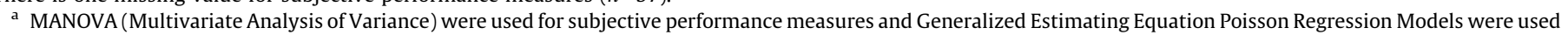
for objective performance. 
Table 2

Training effects on residents' physiological arousal in a breaking bad news simulated task $(n=98)$.

\begin{tabular}{|c|c|c|c|c|c|c|c|c|c|c|}
\hline & \multicolumn{4}{|c|}{ Training group $(n=50)$} & \multicolumn{4}{|c|}{ Control group $(n=48)$} & \multicolumn{2}{|c|}{ MANOVA } \\
\hline & \multicolumn{2}{|c|}{ At baseline } & \multicolumn{2}{|c|}{ After training } & \multicolumn{2}{|c|}{ At baseline } & \multicolumn{2}{|c|}{$\begin{array}{l}8 \text { months after } \\
\text { baseline }\end{array}$} & \multicolumn{2}{|c|}{$\begin{array}{l}\text { Group by time } \\
\text { effects }\end{array}$} \\
\hline & Mean & SD & Mean & SD & Mean & SD & Mean & SD & $F$ & $p$ \\
\hline \multicolumn{11}{|l|}{ Mean heart rate } \\
\hline \multicolumn{11}{|l|}{ Levels } \\
\hline Rest & 82.1 & 8.7 & 81.2 & 11.2 & 81.1 & 10.0 & 79.1 & 10.5 & 0.59 & 0.445 \\
\hline Preparation & 84.7 & 9.3 & 83.4 & 11.3 & 83.1 & 11.9 & 81.1 & 12.7 & 0.12 & 0.728 \\
\hline Simulated task $0-5 \mathrm{~min}$ & 95.6 & 13.1 & 92.8 & 16.2 & 93.3 & 17.2 & 83.1 & 14.0 & 9.89 & 0.002 \\
\hline Simulated task $5-10 \mathrm{~min}$ & 85.7 & 10.8 & 85.6 & 13.5 & 85.9 & 13.0 & 79.6 & 11.8 & 11.55 & 0.001 \\
\hline Simulated task $10-15 \mathrm{~min}$ & 83.4 & 9.3 & 82.4 & 11.7 & 83.1 & 10.8 & 78.8 & 10.4 & 4.08 & 0.046 \\
\hline Simulated task $15-20 \mathrm{~min}$ & 82.0 & 9.8 & 82.2 & 11.0 & 81.8 & 10.6 & 77.9 & 10.0 & 7.53 & 0.007 \\
\hline Recuperation $0-10 \mathrm{~min}$ & 78.2 & 8.2 & 77.9 & 9.8 & 77.4 & 9.2 & 76.0 & 9.6 & 0.73 & 0.396 \\
\hline Recuperation $10-20 \mathrm{~min}$ & 76.1 & 7.7 & 75.8 & 10.1 & 75.9 & 8.9 & 74.0 & 9.9 & 1.60 & 0.208 \\
\hline Recuperation $20-30 \mathrm{~min}$ & 76.1 & 7.6 & 75.9 & 9.9 & 75.8 & 9.2 & 74.4 & 10.0 & 0.73 & 0.395 \\
\hline \multicolumn{11}{|l|}{ Changes } \\
\hline Preparation - rest & 2.8 & 4.4 & 2.5 & 4.6 & 1.8 & 4.2 & 1.7 & 4.2 & 0.04 & 0.835 \\
\hline Simulated task $0-5-$ preparation & 10.7 & 10.1 & 9.4 & 11.9 & 11.2 & 10.6 & 2.5 & 6.9 & 12.82 & 0.001 \\
\hline Simulated task 5-10 - task 0-5 & -9.9 & 5.4 & -7.2 & 7.7 & -7.4 & 6.5 & -3.5 & 4.2 & 0.70 & 0.406 \\
\hline Simulated task $10-15-$ task $5-10$ & -2.3 & 3.5 & -3.2 & 5.2 & -2.8 & 4.8 & -0.7 & 3.3 & 8.82 & 0.004 \\
\hline Simulated task $15-20-$ task $10-15$ & -1.5 & 3.0 & -0.2 & 3.3 & -1.3 & 2.8 & -0.9 & 2.2 & 1.62 & 0.206 \\
\hline Recuperation $0-10$ - task $15-20$ & -3.8 & 4.3 & -4.3 & 4.7 & -4.4 & 5.0 & -1.9 & 4.0 & 15.89 & $<0.001$ \\
\hline Recuperation $10-20$ - recuperation $0-10$ & -2.1 & 2.2 & -2.1 & 3.0 & -1.5 & 2.1 & -2.0 & 2.6 & 0.84 & 0.361 \\
\hline Recuperation $20-30$ - recuperation $10-20$ & -0.1 & 1.8 & 0.2 & 2.3 & -0.3 & 2.3 & 0.4 & 2.8 & 0.24 & 0.625 \\
\hline Recuperation $20-30$ - rest & -6.1 & 4.2 & -5.6 & 5.1 & -5.8 & 4.8 & -4.8 & 4.5 & 0.14 & 0.713 \\
\hline \multicolumn{11}{|l|}{ Salivary cortisol } \\
\hline \multicolumn{11}{|l|}{ Areas under the curve } \\
\hline Rest to end of preparation & 32.4 & 22.0 & 44.9 & 28.0 & 31.6 & 14.0 & 32.4 & 18.4 & 5.12 & 0.026 \\
\hline End of preparation to end of simulated task & 130.5 & 81.7 & 166.5 & 100.8 & 119.4 & 57.2 & 121.2 & 66.5 & 4.10 & 0.046 \\
\hline End of simulated task to recuperation $10 \mathrm{~min}$ & 64.4 & 47.5 & 75.3 & 47.1 & 56.4 & 33.2 & 54.9 & 28.6 & 2.16 & 0.145 \\
\hline Recuperation 10 to recuperation $30 \mathrm{~min}$ & 105.8 & 73.2 & 131.3 & 77.5 & 95.4 & 53.4 & 99.1 & 48.2 & 2.32 & 0.131 \\
\hline Rest to recuperation $30 \mathrm{~min}$ & 346.0 & 219.0 & 441.3 & 247.6 & 312.1 & 152.3 & 307.5 & 159.4 & 4.61 & 0.035 \\
\hline
\end{tabular}

There are for several periods some missing values $(\max =13)$.

their third year ( $\mathrm{SD}=1.2$ years) of residency. Twenty-five percent were in oncology, $21 \%$ in gynaecology and $54 \%$ in other specialties. Trained residents took part on average in $25 \mathrm{~h}$ of training $(\mathrm{SD}=8.1)$. They participated to $8 \mathrm{~h}$ of stress management skills training $(\mathrm{SD}=2.4)$ and to $17 \mathrm{~h}$ of communication skills training $(\mathrm{SD}=6.8)$.

\subsection{Training effects on residents' performance}

As shown in Table 1 and as it has already been shown elsewhere [33], MANOVA showed significant or marginal group-by-time effects on residents' subjective (self-efficacy about communication and satisfaction about performance) and objective performance
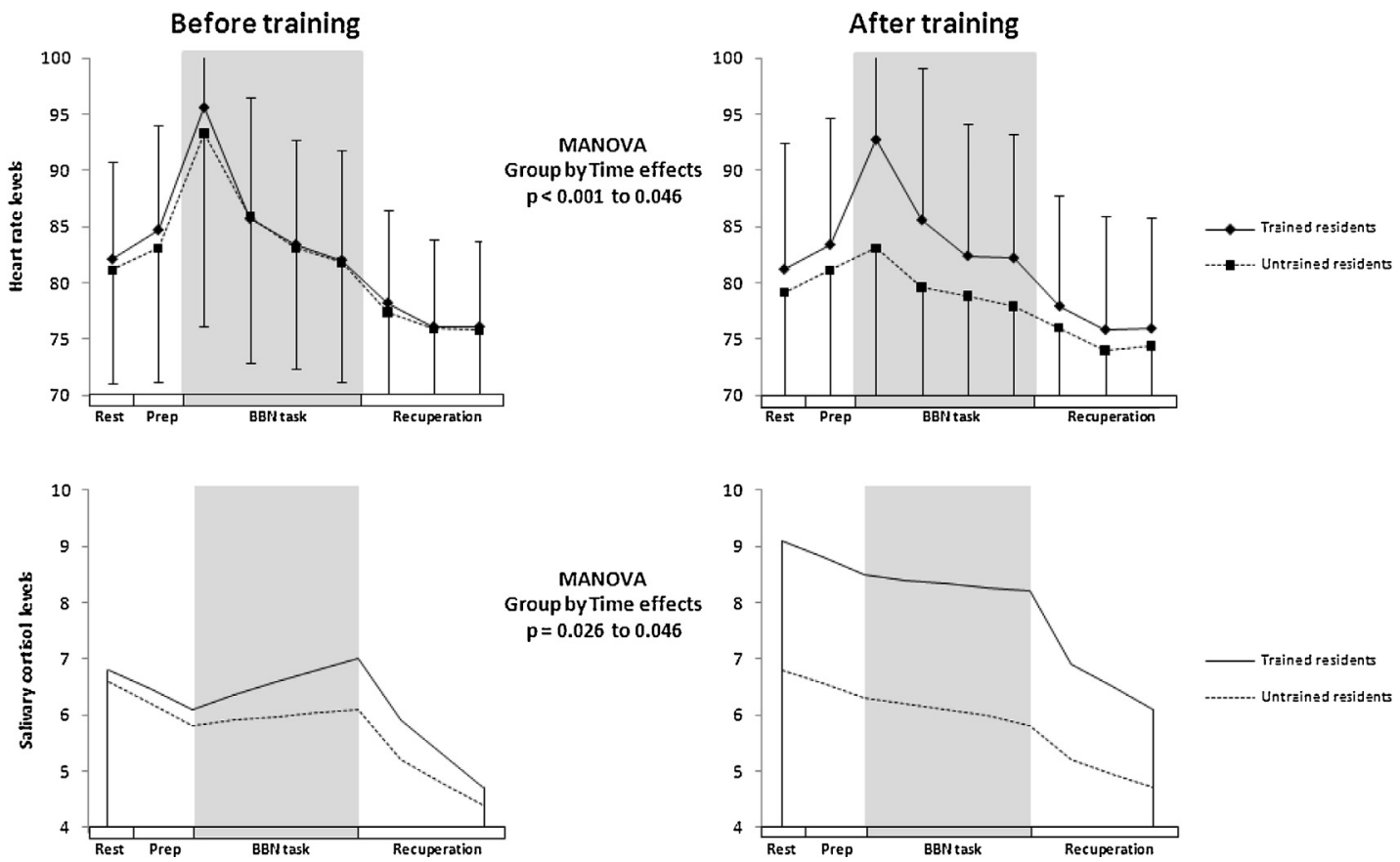

Fig. 5. Heart rate levels (mean heart beats per minute) and salivary cortisol levels (areas under the response curve). 
(increase in assessment and support and decrease in information giving).

\subsection{Training effects on residents' physiological arousal}

The General Linear Model assessing over time and between group's changes (Phases by Time by Group) is highly significant $(p<.0001$; partial eta square $=.095$; power $=.999)$. As shown in Table 2 and in Fig. 5, MANOVA showed significant group-by-time effects on residents' physiological arousal levels. Residents' mean heart rate levels remained elevated after training for trained residents compared to untrained residents whose mean heart rate levels decreased. Trained residents' mean heart rate levels were higher during the 20-min BBN simulated task than untrained residents' mean heart rate levels. Moreover, trained residents' mean heart rate changes were higher between preparation and the BBN simulated task 0-5 min, between the BBN simulated task 510 min and the BBN simulated task $10-15$ min and between the BBN simulated task 15-20 min and recuperation 0-10 min than untrained residents mean heart rate changes. Finally, trained residents' cortisol AUCs were higher between rest and end of preparation, between end of preparation and end of BBN simulated task, and between rest and recuperation $30 \mathrm{~min}$ than untrained residents' cortisol AUCs. No group by time change was observed in terms of the confounding variables tested in the study (medication, food, alcohol, caffeine taken during the $24 \mathrm{~h}$ before the assessment procedure and number of hours of physical activity and sleep during the $24 \mathrm{~h}$ before the assessment procedure) except for nicotine consumption ( $p=0.037)$. Four trained residents and 2 untrained residents began smoking between T1 and T2.

\section{Discussion and conclusion}

\subsection{Discussion}

This is the first study assessing, in a randomized controlled trial design, the effect of communication skills training on residents' physiological arousal in a BBN simulated. Results of this study show that a communication skills training has an effect on residents' physiological arousal in a BBN simulated task. The hypothesis that trained residents will present an elevated physiological arousal when they engage in and perform the task compared to untrained residents has been confirmed.

As shown in Fig. 5, heart rate and cortisol levels have different patterns of change over time. For heart rate, there is a change (decreased level) in the waiting list group between pre- and posttest, but no change in the training group. For cortisol level, there is a change (increased level) in the training group but not in the waiting list group. The pattern of change over time of heart rate and cortisol levels should thus be interpreted separately.

The pattern of change of heart rate found in this study supports the idea that an elevated heart rate may reflect, either an arousal in an unknown and stressful test context (for both groups of residents at baseline) [16,47], or an arousal which is an indicator of an engagement to respond adequately to the task using newly learned communication skills while maintaining step-by-step attention to the task challenges (for trained residents). It should be recalled that, before training, residents have limited communication skills. As it could be expected, the results of this study show that, before training, an elevated heart rate in residents during the task is related to the exposure to an unknown and stressful task. Results of this study show that, after training, heart rate is more elevated in trained residents compared to untrained residents. This higher elevation in heart rate in trained residents - which is associated with higher self-efficacy and satisfaction about their performance in the task, with less stress to communicate [33] and with an improvement in residents communication skills [22] - may be an indicator, as hypothesized, of their engagement in performing the task. An additional explanation for these higher elevations in trained residents' heart rate may be that trained residents are more aware of the challenges of BBN and the impact for the patient of poor communication and may therefore be more motivated to engage in the task. The lower level of elevation in heart rate in untrained residents may be explained by the fact that, being for a second time exposed to an already experimented task - that they have not learned to perform better - residents deal with the task as they do "usually". An additional explanation for this lower elevation in untrained residents' heart rate may be residents' habituation to the simulated task [11].

The pattern of change over time of cortisol levels found in this study supports the idea that the elevated levels of cortisol found after training reflect the physiological arousal related to the sustained cognitive and emotional activation - starting already before the task - of residents and may be an indicator of their preparation and engagement to respond adequately to the task while maintaining step-by-step attention to the task challenges. The lower cortisol levels found in residents, at baseline for both groups and at post-test in untrained residents, may reflect a lower level of cognitive and emotional activation because they are probably dealing with the task as they do "usually".

\subsection{Conclusions}

To summarize, when trained residents perceive that they are more able to perform the task (with higher level of self-efficacy about communication [33]), they engage in and perform the task better (with improvements in observed communication skills [22]) and their physiological arousal levels are consequently elevated. Their physiological arousal becomes probably more proportional to the complexity of the task and reflects cognitive and emotional activation to engage in the task and to respond with learned communication skills to task challenges. These results are similar with results of other studies that have shown a link between performance and arousal [24-27].

The strength of this study is that residents' performance and physiological arousal were assessed before, during and after a standardized BBN simulated task with reliable measures like heart rate and salivary cortisol levels. Heart rate and cortisol were selected because they are able to reflect reliably changes over time during a given task and for a given task repeated over time (heart rate as a fast response measure and cortisol as a slow response measure - 20-40 min - after a stimulation). In particular measures of cortisol levels were selected as it has been suggested that cortisol levels are a "useful index of subjective stress" [48], allow to "assess relationship between perceived stress, activation and performance" [49], and are related to "cognitive performance" [50].

The study has some limitations. First, it should be recalled that physicians were voluntarily enrolled and were mainly inexperienced clinicians. This fact limits the generalizability of our results. It could be argued also that the motivation of those physicians was high and that this could have had an impact on the training effects observed. Second, this study investigated changes immediately after training. The arousal levels found are therefore related to an early learning stage, which still needs a controlled processing in the execution of the task. It may be hypothesized that in more advanced learning stages - after a few years of practice for example - this arousal level would not be found anymore given the fact that a constant attentional control would not be needed anymore. Third, the extremely low response rate to the study should be underlined. This may be due to a too large and non-personalized recruitment procedure. Result of this study may thus reflect results 
of more motivated and less anxious residents. Fourth, this study focused on residents' verbal communication. Future studies should include the assessment of non-verbal communication. Fifth, it should be noted that the fact that residents filled in questionnaires during the recuperation phase may have increased their autonomic arousal levels.

\subsection{Practice implications}

What could be the practical implications of these results for residents? Residents consider usually that to perform a complex task such as a BBN task (highly difficult cognitively and emotionally), they need to acquire a feeling of self-efficacy about the task and to learn skills to perform the task properly. Results of this study confirm that residents could benefit from being informed that they also need to engage in the task with a physiological arousal proportional to the complexity of the BBN task. What could be the practical implications of these results for trainers? Trainers usually consider that to perform a complex task such as a BBN task, they have to develop residents' feeling of selfefficacy about the task and to teach skills to perform the task properly. Given the results of this study, it may be hypothesized that they should teach residents to engage actively in the task with a physiological arousal proportional to the complexity of the BBN task. To achieve that, trainers may use role playing exercises with increased degrees of complexity, debrief residents at each step of these role-plays and teach residents specific skills to deal with difficulties met at each of these steps. This would be interesting areas to address in future research designed to improve communication skills training efficacy $[51,52]$.

\section{Acknowledgements}

This research program was supported by the "Fonds National de la Recherche Scientifique - Section Télévie" of Belgium and by the C.P.O., training and research group (Brussels-Belgium). The study sponsors had no role in study design, data collection, data analysis, or data interpretation, or in the preparation, review, or approval of the report.

The authors have no financial and personal relationships with other people or organizations that could inappropriately influence their work. Principal investigator had full access to all the data in the study and takes responsibility for the integrity of the data and the accuracy of the data analysis.

\section{References}

[1] Bredart A, Bouleuc C, Dolbeault S. Doctor-patient communication and satisfaction with care in oncology. Curr Opin Oncol 2005;17:351-4.

[2] Stavropoulou C. Non-adherence to medication and doctor-patient relationship: evidence from a European survey. Patient Educ Couns 2011;83:7-13.

[3] Albrecht TL, Eggly SS, Gleason ME, Harper FW, Foster TS, Peterson AM, et al. Influence of clinical communication on patients' decision making on participation in clinical trials. J Clin Oncol 2008;26:2666-73.

[4] Brown VA, Parker PA, Furber L, Thomas AL. Patient preferences for the delivery of bad news - the experience of a UK Cancer Centre. Eur J Cancer Care (Engl) $2011 ; 20: 56-61$.

[5] Eggly S, Penner L, Albrecht TL, Cline RJ, Foster T, Naughton M, et al. Discussing bad news in the outpatient oncology clinic: rethinking current communication guidelines. J Clin Oncol 2006;24:716-9.

[6] Fallowfield L, Jenkins V. Communicating sad, bad, and difficult news in medicine. Lancet 2004:363:312-9.

[7] Ptacek JT, Eberhardt TL. Breaking bad news. A review of the literature. J Amer Med Assoc 1996;276:496-502.

[8] Sweeny K, Shepperd JA. Being the best bearer of bad tidings. Rev Gen Psychol 2007; 11:235-57.

[9] Brown R, Dunn S, Byrnes K, Morris R, Heinrich P, Shaw J. Doctors' stress responses and poor communication performance in simulated bad-news consultations. Acad Med 2009;84:1595-602.

[10] Cohen L, Baile WF, Henninger E, Agarwal SK, Kudelka AP, Lenzi R, et al. Physiological and psychological effects of delivering medical news using a simulated physician-patient scenario. J Behav Med 2003;26:459-71.
[11] Hulsman RL, Pranger S, Koot S, Fabriek M, Karemaker JM, Smets EM. How stressful is doctor-patient communication? Physiological and psychological stress of medical students in simulated history taking and bad-news consultations. Int J Psychophysiol 2010;77:26-34.

[12] van Dulmen S, Tromp F, Grosfeld F, ten Cate O, Bensing J. The impact of assessing simulated bad news consultations on medical students' stress response and communication performance. Psychoneuroendocrinology 2007;32:943-50.

[13] Tomaka J, Blascovich J, Kibler J, Ernst JM. Cognitive and physiological antecedents of threat and challenge appraisal. J Pers Soc Psychol 1997;73:63-72.

[14] Blascovich J, Mendes WB. Challenge and threat appraisals: the role of effective cues. In: Forgas J, editor. Feeling and thinking: the role of affect in social cognition. New York: Cambridge University Press; 2000. p. 59-82.

[15] Staal MA. Stress, cognition, and human performance: a litterature review and conceptual framework. Moffett Field, CA: NASA/TM; 2004.

[16] Gaillard AWK. Stress, workload, and fatigue as three biobehavioral states: a general overview. In: Hancock PA, Desmond PA, editors. Stress, workload and fatigue. Mahwah (NJ), London: Lawrence Erlbaum Associates; 2001 p. 623-49.

[17] Lazarus RS, Folkman S. Stress, appraisal, and coping. New York: Springer Publishing Company; 1984.

[18] Everly GS, Lating JM. A clinical guide to the treatment of the human stress response. In: Meichenbaum D, editor. The Plenum series on stress and coping. New York: Kluwer Academic/Plenum Publishers; 2002.

[19] Ammentorp J, Sabroe S, Kofoed PE, Mainz J. The effect of training in communication skills on medical doctors' and nurses' self-efficacy. A randomized controlled trial. Patient Educ Couns 2007;66:270-7.

[20] Barth J, Lannen P. Efficacy of communication skills training courses in oncology: a systematic review and meta-analysis. Ann Oncol 2011;22:1030-40.

[21] Lienard A, Merckaert I, Libert Y, Bragard I, Delvaux N, Etienne AM, et al. Transfer of communication skills to the workplace during clinical rounds: impact of a program for residents. PLoS ONE 2010;5:e12426.

[22] Lienard A, Merckaert I, Libert Y, Bragard I, Delvaux N, Etienne AM, et al. Is it possible to improve residents breaking bad news skills? A randomised study assessing the efficacy of a communication skills training program. Brit J Cancer 2010;103:171-7.

[23] Yerkes RM, Dodson JD. The relation of strength of stimulus to rapidity of habitformation. J Comp Neurol Psychol 1908;18:459-82.

[24] Calabrese EJ. Converging concepts: adaptive response, preconditioning, and the Yerkes-Dodson Law are manifestations of hormesis. Ageing Res Rev 2008;7:8-20.

[25] Diamond DM, Campbell AM, Park CR, Halonen J, Zoladz PR. The temporal dynamics model of emotional memory processing: a synthesis on the neurobiological basis of stress-induced amnesia, flashbulb and traumatic memories, and the Yerkes-Dodson law. Neural Plast 2007;60803. 33 p..

[26] Gendolla GH, Richter M, Silvia PJ. Self-focus and task difficulty effects on effortrelated cardiovascular reactivity. Psychophysiology 2008;45:653-62.

[27] Matheson K, Gill R, Kelly O, Anisman H. Cortisol and cardiac reactivity in the context of sex discrimination: the moderating effects of mood and perceived control. Open Psychol J 2008;1:1-10.

[28] Yeo GB, Neal A. A multilevel analysis of effort, practice, and performance: effects; of ability, conscientiousness, and goal orientation. J Appl Psychol 2004;89:231-47.

[29] Clow A. The physiology of stress. In: Jones F, Bright J, editors. Stress: myth, theory and research. Harlow: Pearson Education; 2001. p. 47-61.

[30] Lacey BC, Lacey JL. Studies of heart rate and other bodily processes in sensorimotor behavior. In: Obrist PA, Black AH, Brener J, DiCara LV, editors. Cardiovascular psychophysiology. Chicago: Aldine Publishing Co.; 1974. p. 538-64.

[31] Cacioppo JT, Sandman CA. Physiological differentiation of sensory and cognitive tasks as a function of warning, processing demands, and reported unpleasantness. Biol Psychol 1978;6:181-92.

[32] Peters ML, Godaert GLR, Ballieux RE, van Vliet M, Willemsen JJ, Sweep FCGJ, et al. Cardiovascular and endocrine responses to experimental stress: effects of mental effort and controllability. Psychoneuroendocrinology 1998;23:1-17.

[33] Bragard I, Etienne AM, Merckaert I, Libert Y, Razavi D. Efficacy of a communication and stress management training on medical residents' self-efficacy, stress to communicate and burnout: a randomized controlled study. J Health Psychol 2010;15:1075-81.

[34] Roter DL, Hall JA, Kern DE, Barker LR, Cole KA, Roca RP. Improving physicians interviewing skills and reducing patients emotional distress - a randomized clinical-trial. Arch Intern Med 1995;155:1877-84.

[35] Delvaux N, Merckaert I, Marchal S, Libert Y, Conradt S, Boniver J, et al. Physicians' communication with a cancer patient and a relative: a randomized study assessing the efficacy of consolidation workshops. Cancer 2005;103:2397-411.

[36] Razavi D, Merckaert I, Marchal S, Libert Y, Conradt S, Boniver J, et al. How to optimize physicians' communication skills in cancer care: results of a randomized study assessing the usefulness of posttraining consolidation workshops. J Clin Oncol 2003;21:3141-9.

[37] Bragard I, Razavi D, Marchal S, Merckaert I, Delvaux N, Libert Y, et al. Teaching communication and stress management skills to junior physicians dealing with cancer patients: a Belgian Interuniversity Curriculum. Support Care Cancer 2006;14:1-8.

[38] Maguire P, Faulkner A, Booth K, Elliott C, Hillier V. Helping cancer patients disclose their concerns. Eur J Cancer 1996;32A:78-81.

[39] Parle M, Maguire P, Heaven C. The development of a training model to improve health professionals' skills, self-efficacy and outcome expectancies when communicating with cancer patients. Soc Sci Med 1997;44:231-40. 
[40] Spielberger CD, Gorusch RR, Lushene RE, Vagg PR. Manual for the State-Trait Anxiety Inventory STAI-form Y. Paolo Alto: Consulting Psychologists Press Inc.; 1983.

[41] Spielberger CD, Bruchon-Schweitzer M, Paulhan I. Inventaire d'anxiété EtatTrait Forme Y (STAY-Y). Paris: Les Editions du Centre de Psychologie Appliquée; 1993.

[42] Hogenraad R, Daubies C, Bestgen Y. Une théorie et une méthode générale d'analyse textuelle assistée par ordinateur: le Système PROTAN (PROTocol ANalyser). Louvain-la-Neuve: Université Catholique de Louvain, Psychology Department; 1995.

[43] Pennebacker JW, Booth RE, Francis ME. Linguistic inquiry and word count: LIWC2007 - operator's manual. Austin, TX: LIWC.net; 2007.

[44] Stone P, Dunphy D, Smith M, Ogilvie D. The general inquirer: a computer approach to content analysis. Cambridge, MA: MIT Press; 1966.

[45] Richter M, Friedrich A, Gendolla GH. Task difficulty effects on cardiac activity. Psychophysiology 2008;45:869-75.
[46] Pruessner JC, Kirschbaum C, Meinlschmid G, Hellhammer DH. Two formulas for computation of the area under the curve represent measures of total hormone concentration versus time-dependent change. Psychoneuroendocrinology $2003 ; 28: 916-31$.

47] Lazarus RS. Theory based stress measurement. Psychol Inquiry 1990;1:3-13.

[48] Bohnen N, Nicolson N, Sulon J, Jolles J. Coping style, trait anxiety and cortisol reactivity during mental stress. J Psychosom Res 1991;35:141-7.

[49] al'Absi M, Hugdahl K, Lovallo WR. Adrenocortical stress responses and altered working memory performance. Psychophysiology 2002;39:95-9.

[50] Vedhara K, Hyde J, Gilchrist ID, Tytherleigh M, Plummer S. Acute stress, memory, attention and cortisol. Psychoneuroendocrinology 2000;25:535-49.

[51] Merckaert I, Libert Y, Razavi D. Communication skills training in cancer care: where are we and where are we going? Curr Opin Oncol 2005;17:319-30.

[52] Uitterhoeve RJ, Bensing JM, Grol RP, Demulder PHM, Van achterberg T. The effect of communication skills training on patient outcomes in cancer care: a systematic review of the literature. Eur J Cancer Care (Engl) 2010;19:442-57. 